\title{
OPERATIVE OUTCOME OF ACUTE EXTRADURAL HAEMATOMA, OPERATED AT DIFFERENT TIME INTERVAL AND REVIEW OF INTERNATIONAL GUIDELINES
}

\author{
MME HAQUE ${ }^{1}$, S SULTANA ${ }^{2}$, SU AHAMED ${ }^{3}$, MAALAMGIR $^{4}$
}

\begin{abstract}
:
Objective: To determine the prognostic factors of the functional outcome of patients surgically treated for acute extradural haematoma.

Method: Sixty three cases of extradural haematoma was studied over a period of two years from July 2001 to July 2003 in dept of neurosurgery Dhaka Medical college \& Hospital. Study was prospective for their clinical profile and operative measures. Clinical characteristics, radiologic findings, and the time intervals with regard to treatment course were investigated to determine the interactions between all these factors and functional outcome. Their clinical presentation varied from intense headache to deep coma and fixed pupil. Patients were divided into two groups on the basis of the GCS level on admission and also on the basis of the operative time interval. All patients were treated surgically and haematoma evacuated.
\end{abstract}

Results: Out of 63 cases 26 cases $(41.3 \%)$ were in $3^{\text {rd }}$ decade. Male to female ratio was $14: 1$, where males were $93.6 \%$ (59 cases) out of total 63 . Most common mode of injury causing EDH was due to RTA $57 \%$ followed by assault $(26.9 \%) \&$ fall from height $(15.8 \%)$. CT scan confirms site of EDH which was more common in

1. MME Haque, Associate Professor, Department of Neurosurgey, Sher-E-Bangla Medical College \& Hospital, Barisal

2. Sultana S, Assistant Professor, Department of Ophthalmology, Shahid Sohrawardi Medical Collrge \& Hospital, Dhaka

3. Ahamed SU, Ex. Professor \& Head, Department of Neurosurgey, Dhaka Medical College \& Hospital, Dhaka

4. Md. Abdullah Alamgir, Neurosurgeon, Dept. of Neurosurgery, Dhaka Medical College \& Hospital, Dhaka

Correspondence: Dr.M.M.Ehsanul Haque, M.S(Neurosurgery), Associate Professor \& Head (Neurosurgery), Sher-E-Bangla Medical College \& Hospital, Barisal, Bangladesh. Email-muntaka26@yahoo.com temporal region in 26 cases(41.2\%) followed by frontal 13 cases $(20.6 \%)$, parietal 11 cases $(17.4 \%)$, temporoparietal region 10 cases $(15.8 \%) \&$ occipital region 3 cases $(4.76 \%)$. The mean interval between injury and operation in two groups were 36 hours \& 5 days(Av). Most important finding was the operative outcome where mortality was $\mathbf{3 0 . 1 \%}$.This mortality was dependent on the GCS level rather than the preoperative time. But the number of patients achieved good recovery ( resume normal life GOS 5) was significantly more among them who were treated within 3 days (mean 24.15 hours) than those who were treated within 5.26 days .

Conclusion: This study identifies the risk factors involved in the functional outcome of patients who underwent surgical treatment for acute epidural hematomas. Excessive delay occurred in recognizing the condition and in subsequent transfer of patients. Early intervention in traumatic EDH cases should not be delayed. It gives not only the better result but also reduces the number of disabled vegetative person and reduces morbidity and above all reduces social burden, hospital staying and cost.

Key Words: EDH, Middle meningeal artery, RTA. GCS, GOS.

\section{Introduction:}

Traumatic injuries are a major public health problem, imposing a greater burden on modern society than other diseases. In children and in adults under age 45 injuries remain the major leading cause of death in developed country. ${ }^{1}$ Extradural haematoma is an infrequent sequel of head injury occurring in less than $2 \%$ of hospital admitted cases with craniocerebral trauma ${ }^{2}$. It constitutes the major source of preventable mortality of head injury patients. ${ }^{3}$ Mortality rates vary from $10-40 \%$ in head injury with extradural 
heamatoma ${ }^{4}$. It may be quite high in developing country like ours where no actual statistical data is yet available. The number is more when assault and other causes of injuries are taken into consideration.

The rate of development of signs and symptoms generally depend on the time elapsed between injury and operation. Usually the interval between injury and operation is shorter in comatose patient than non comatose patients. The longer the interval, the better the final outcome reflecting less severe injury. ${ }^{5} 6$ Less severely injured patients are probably more late. So often no correlation exits between the operational time (interval between the injury and operation) and degree of injury. This invariably affects the outcome of our patients. Moreover many of our patients cannot avail ICU facilities.

So present study was done to find out the postoperative status of the head injured patients with EDH where surgical intervention was done at early possible but variable intervals after reaching the patient in Neurosurgery unit of $\mathrm{DMCH}$ from different corners of the country. It also helps to find out the logic to impart the starting of initial aggressive treatment to reduce the secondary brain injury to all medical personnel before referring the patients.

\section{Clinical Materials \& Methods:}

Between July, 2001 to July 2003 total 63 patients diagnosed both clinically and radiologically as a case of traumatic EDH, were managed surgically in department of neurosurgery, Dhaka Medical college and Hospital. This prospective study includes these consecutive patients.

A meticulous examination with an emphasis on neurological function was performed on admission, prior to surgical intervention $\&$ on $8^{\text {th }}$ post operative day, during the time of discharge and follow up after one month.

On the basis of the consciousness level on admission patients were divided in to 4 groups.

$\begin{array}{lll}\text { Group- I } & \text { GCS } & <5 \\ \text { Group- II } & \text { GCS } & 5-8 \\ \text { Group- III } & \text { GCS } & 9-12 \\ \text { Group- IV } & \text { GCS } & 13-15\end{array}$

On the basis of pre operative time interval, they were grouped as

Those - where surgical intervention was done within 3 days of injury.
Those- Where surgical intervention was done from $4^{\text {th }}$ to $7^{\text {th }}$ day of injury.

The diagnosis of EDH was made by non contrast CT scan in all patients. In addition, to standard epidemiological data including age, sex and cause of injury, the level of consciousness(G.C.S), pupillary reaction to light, other associated injury, localization of haematoma, the effect of injury and time elapsed from injury to surgery was recorded. Acute EDH cases were selected with no other significant brain lesions. Patients with spontaneous EDH or EDH of unknown etiology and patients treated conservatively were excluded from the study. Depending on the emergency, surgeries were adjusted as bur hole craniotomy or craniectomy and evacuation of haematoma.Outcome was assessed and the GOS(Glasgow outcome scale) was utilized for the evaluating the outcome.

\section{Results:}

A total of 63 acute EDH cases were studied where most of the patients belonged to the decades of most active \& productive period of life. Highest percentage of patients that is 26 cases $(41.3 \%)$ belonged to $3^{\text {rd }}$ decade and 44 cases $(69.8 \%)$ were in their most active period of life. Males were the major sufferers of the diseases, 59 cases $(93.6 \%)$ and male to female ratio was $14: 1$ in our study.

We found traumatic EDH was mostly due to RTA ( $57 \%$ ), followed by assault $(26.9 \%)$ and fall from height $15.8 \%$. According to CT scan finding 26 cases $(41.2 \%)$ of the EDH was located in the temporal region; followed by frontal 13 cases $(20.6 \%)$, parietal 11 cases $(17.4 \%)$, temporoparietal 10 cases $(15.8 \%)$, and occipital region 3 cases $(4.76 \%)$. GCS of the patients were recorded on admission as $5(7.9 \%)$ cases with $\mathrm{GCS}<5$, $15(23.8 \%)$ with GCS 5-8, 29(46\%) with GCS 9-12 and $14(22.2 \%)$ with GCS 13-15. But prior to operation we found $17(26.9 \%)$ patients with GCS 5-8, 30 (47.6\%) with GCS $9-12$ and 11 (17.5\%) with GCS 13-15. This showed that consciousness level was deteriorating in $9.5 \%$ of patients without having decompressive surgery. Patients with associated injuries like linear or depressed fracture of skull in 43 cases $(68.3 \%)$, upper limb injury 5 cases $(7.8 \%) \&$ faciomaxillary injury 4 cases $(6.3 \%)$ were managed as per merit and priority. 

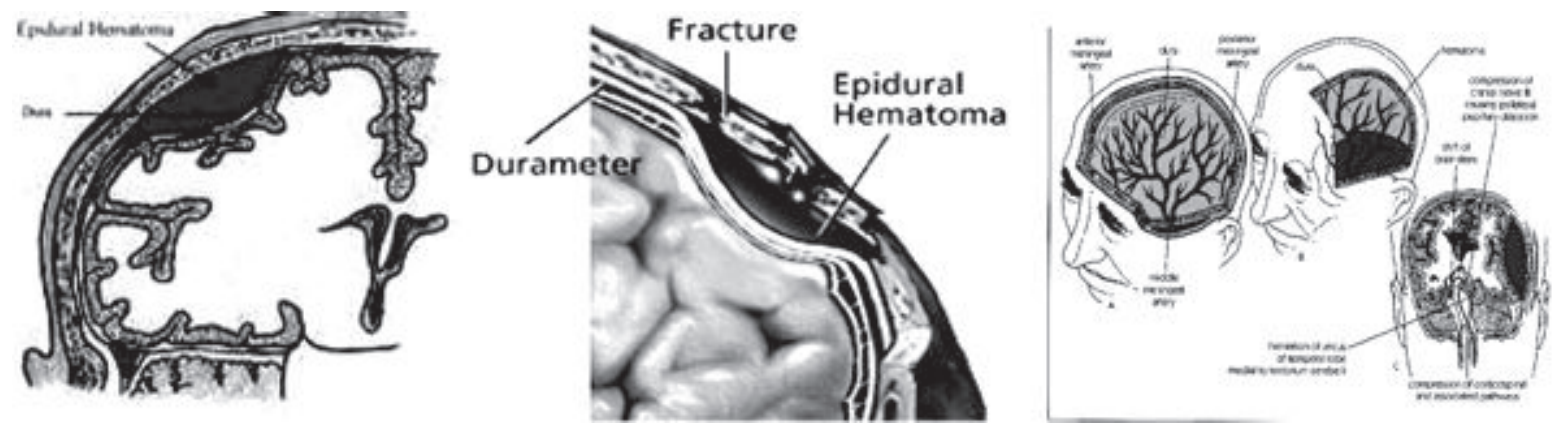

Fig-1: Some diagrammatic picture of EDH 3 Dimensional CT Scan of brain with EDH
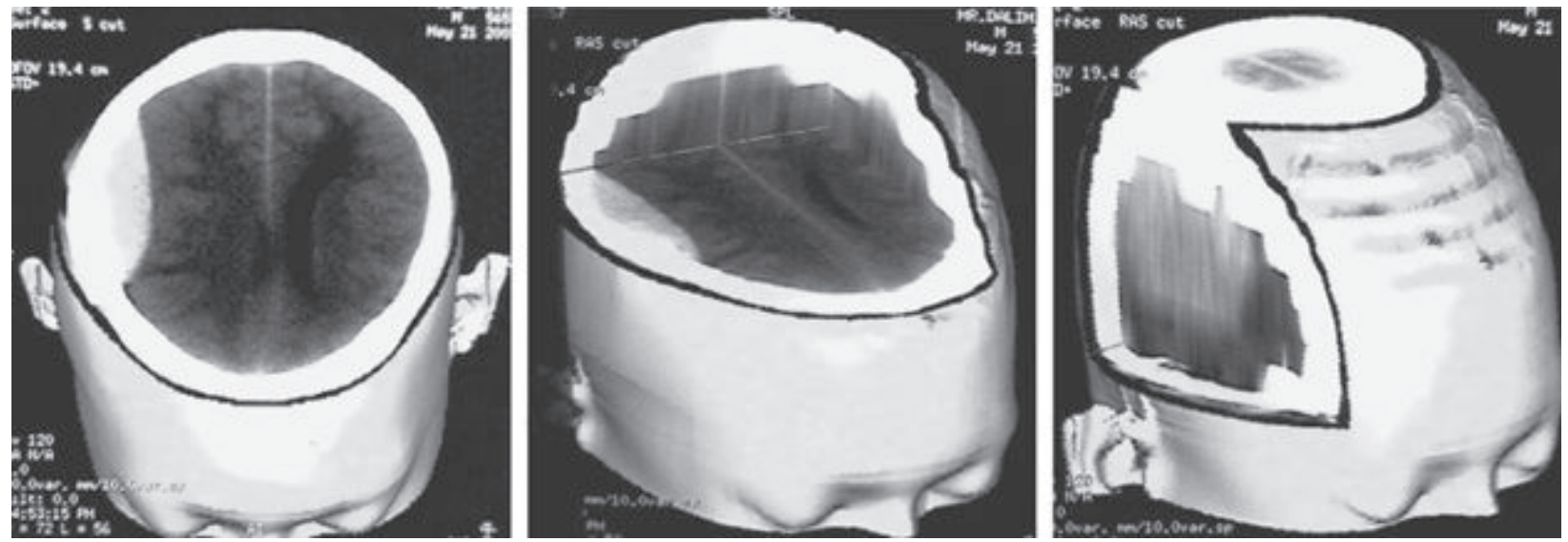

Fig-2: 3Dimensional CT Scan of brain with EDH
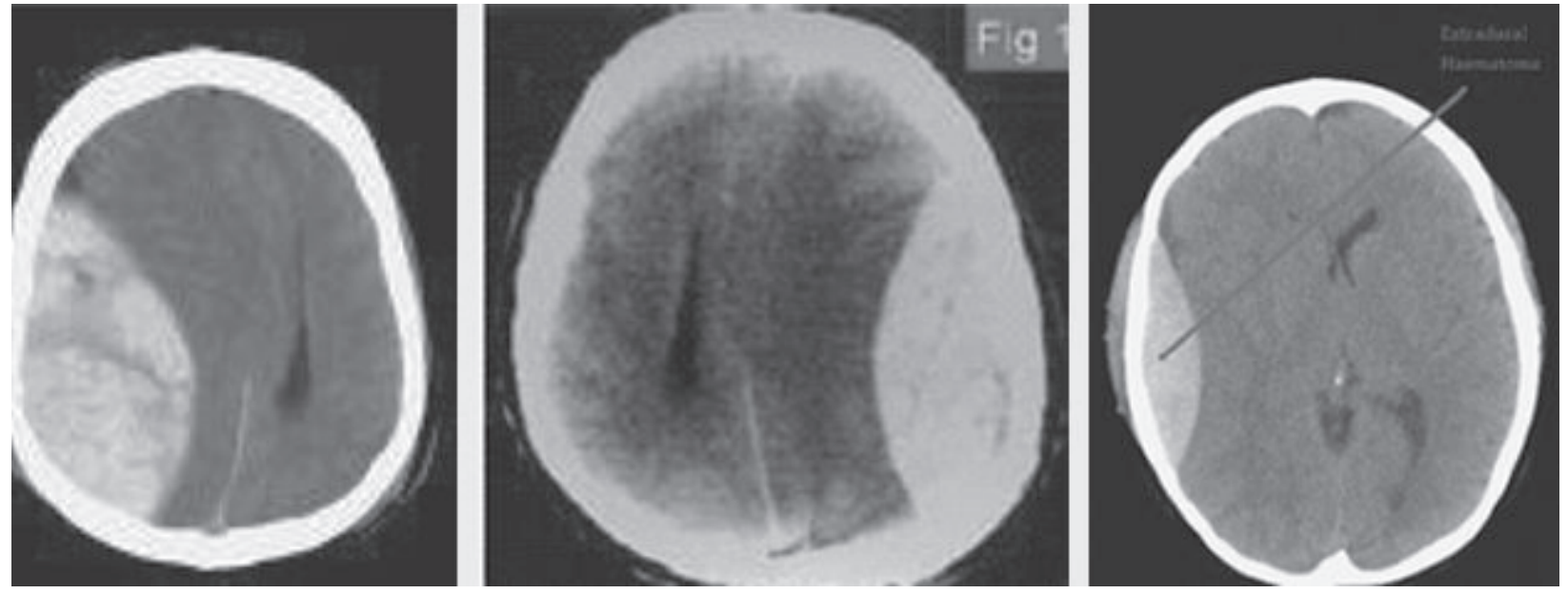

Fig-3: CT Scan of brain with EDH

All the patients were operated. In our series we found overall mortality in 19 cases (30.1\%). All these deaths occur in patients with GCS $<8$ irrespective of time of surgical intervention. There was no difference in outcome among the patients in coma and GCS $<8$ between the two groups of patients where the mean interval between the injury and operation was significantly different, but we found a significant difference in outcome in patients with GCS 9-12 or GCS 13-15 depending on the time of surgical intervention. Among the patients who were not comatose on admission, a good recovery (resume normal life) occurs in 24 ( $38 \%$ ) cases in total. Among 30 patients with GCS $9-12,19$ were operated in 
mean interval of $24.1 \mathrm{hrs}$ and 11 patients were operated in interval of 5 days. 13 patients

$(20.6 \%)$ out of 19 achieved good recovery and 6 cases ( $9.5 \%)$ achieved moderate disability.

On the other hand only two cases (3.1\%) among those 11 patients with GCS 9-12 who were operated at interval of 5 days achieved good recovery, 3 cases achieved moderate disability, 2 cases with severe disability and 4 were dead.Patients with GCS score 13-15, when operated earlier (mean interval of $36 \mathrm{hrs}$ ) achieved good recovery in 6 cases $(9.5 \%)$ and in 3 cases $(4.7 \%)$ when operated lately.

Outcome of patients in our series as per GOS (an international practical scales for evaluation of prognosis of severe head injury) was as follows:

1) Good recovery 24 cases (38\%)

2) Moderate disability 11 cases (17.4\%)

3) Severe disability 9 cases $(14.2 \%)$

4) Dead 19 cases (30.1\%)

All these deaths occur in patients GCS less than 8 irrespective of time of surgical intervention.

Table - I

Patients in different groups according to GCS level on admission. $(n=63)$

\begin{tabular}{|c|c|c|c|c|c|c|c|c|}
\hline & \multicolumn{2}{|c|}{ GCS $<5$} & \multicolumn{2}{|c|}{ GCS 5-8 } & \multicolumn{2}{|c|}{ GCS 9-12 } & \multicolumn{2}{|c|}{ GCS 13-15 } \\
\hline & \multicolumn{2}{|c|}{ Group I } & \multicolumn{2}{|c|}{ Group II } & \multicolumn{2}{|c|}{ Group III } & \multicolumn{2}{|c|}{ Group IV } \\
\hline & no & $\%$ & No & $\%$ & no & $\%$ & No & $\%$ \\
\hline No of pts in each group & 5 & $7.9 \%$ & 15 & $23.8 \%$ & 29 & $46 \%$ & 14 & $22.2 \%$ \\
\hline
\end{tabular}

Table - II

Patients in different groups according to GCS level just prior to operation.( $n=63)$

\begin{tabular}{|c|c|c|c|c|c|c|c|c|}
\hline & \multirow{2}{*}{\multicolumn{2}{|c|}{$\begin{array}{l}\text { GCS }<5 \\
\text { Group I }\end{array}$}} & \multicolumn{2}{|c|}{ GCS 5-8 } & \multicolumn{2}{|c|}{ GCS 9-12 } & \multicolumn{2}{|c|}{ GCS 13-15 } \\
\hline & & & & & & & & IV \\
\hline & no & $\%$ & no & $\%$ & no & $\%$ & no & $\%$ \\
\hline No of pts in each group & 5 & 7.9 & 17 & 26.9 & 30 & 47.6 & 11 & 17.5 \\
\hline
\end{tabular}

Table -III

Patients in different groups under went surgery at different interval of time

\begin{tabular}{lcc}
\hline & $\begin{array}{c}\text { Different groups of patients Preoperative time interval } \\
\text { from infliction of injury to surgical intervention. } \\
\text { Within } 72 \text { hours }\end{array}$ & From $^{\text {th }}$ to $7^{\text {th }}$ day \\
\hline I & 3 & 2 \\
II & 12 & 5 \\
III & 19 & 11 \\
IV & 6 & 5 \\
\hline Total & 40 & 23 \\
\hline
\end{tabular}




\section{Table-IV}

Patients in different groups under went burr hole craniectomy and burr hole craniotomy

\begin{tabular}{lcccccc}
\hline \multirow{2}{*}{$\begin{array}{l}\text { Group of } \\
\text { patients }\end{array}$} & \begin{tabular}{c} 
Name of Operations \\
\cline { 2 - 6 }
\end{tabular} & $\begin{array}{c}\text { Burr hole } \\
\text { Craniectomy }\end{array}$ & $\begin{array}{c}\text { Total no of } \\
\text { Craniectomy }\end{array}$ & $\%$ & $\begin{array}{c}\text { Burr hole } \\
\text { Craniotomy }\end{array}$ & $\begin{array}{c}\text { Total no of } \\
\text { craniotomy }\end{array}$ \\
\hline I & 5 & 15 & $23.8 \%$ & & 48 & $76 \%$ \\
II & 10 & & 7 & & \\
III & & & 30 & \\
IV & & & 11 & & \\
\hline
\end{tabular}

Table-V

Average preoperative time interval in two group of patients

\begin{tabular}{|c|c|c|c|c|c|c|c|c|c|c|c|c|}
\hline \multicolumn{8}{|c|}{ Total no of pts $=40$} & \multicolumn{5}{|c|}{ Total no of $=23$} \\
\hline & \multicolumn{7}{|c|}{ Op done in 3 days } & \multicolumn{5}{|c|}{ Op done in 4-7 days } \\
\hline & $0-12 \mathrm{hr}$ & $13-24 \mathrm{hr}$ & $25-36 \mathrm{hr}$ & $36-48 \mathrm{hr}$ & 49-60hr & $61-72 \mathrm{hr}$ & Aver in hrs & $4^{\text {th }}$ days & $5^{\text {th }}$ days & $6^{\text {th }}$ days & $7^{\text {th }}$ dats & Aver in d \\
\hline No & 2 & 12 & 17 & 5 & 3 & 1 & 24.15 & 3 & 13 & 5 & 2 & 5.26 \\
\hline
\end{tabular}

So after ignoring fractions average preoperative time interval $24 \mathrm{hrs} \& 5$ days respectively.

Table-VI

Post operative outcome in different groups of patients as per GOS in $8^{\text {th }} P O D$

\begin{tabular}{|c|c|c|c|c|c|c|}
\hline \multirow{2}{*}{\multicolumn{2}{|c|}{ On $8^{\text {th }}$ POD }} & \multicolumn{3}{|c|}{ Post operative outcome } & \multirow{4}{*}{$\begin{array}{c}\text { Persistant } \\
\text { vegitative state (2) }\end{array}$} & \multirow{4}{*}{$\begin{array}{l}\text { Death } \\
\text { (1) }\end{array}$} \\
\hline & & \multicolumn{3}{|c|}{ Glasgow outcome scale } & & \\
\hline Group of & Preoperative & Good & Moderate & Severe & & \\
\hline patients & time interval & Recovery (5) & Disability (4) & Disability (3) & & \\
\hline \multirow[t]{2}{*}{ I } & Op done in 3 days & & & & & 3 \\
\hline & Op done in $4^{\text {th }}$ to $7^{\text {th }}$ day & & & & & 2 \\
\hline \multirow[t]{2}{*}{$\|$} & Op done in 3 days & & & 7 & & 5 \\
\hline & Op done in $4^{\text {th }}$ to $7^{\text {th }}$ day & & & 1 & & 4 \\
\hline \multirow[t]{2}{*}{ III } & Op done in 3 days & 11 & 8 & & & \\
\hline & Op done in $4^{\text {th }}$ to $7^{\text {th }}$ day & 2 & 3 & 2 & & 4 \\
\hline \multirow[t]{3}{*}{ IV } & Op done in 3 days & 6 & & & & \\
\hline & Op done in $4^{\text {th }}$ to $7^{\text {th }}$ day & 3 & 2 & & & \\
\hline & Total & 2 & 2 & 13 & 0 & 18 \\
\hline
\end{tabular}




\section{Operative outcome on 8th POD}

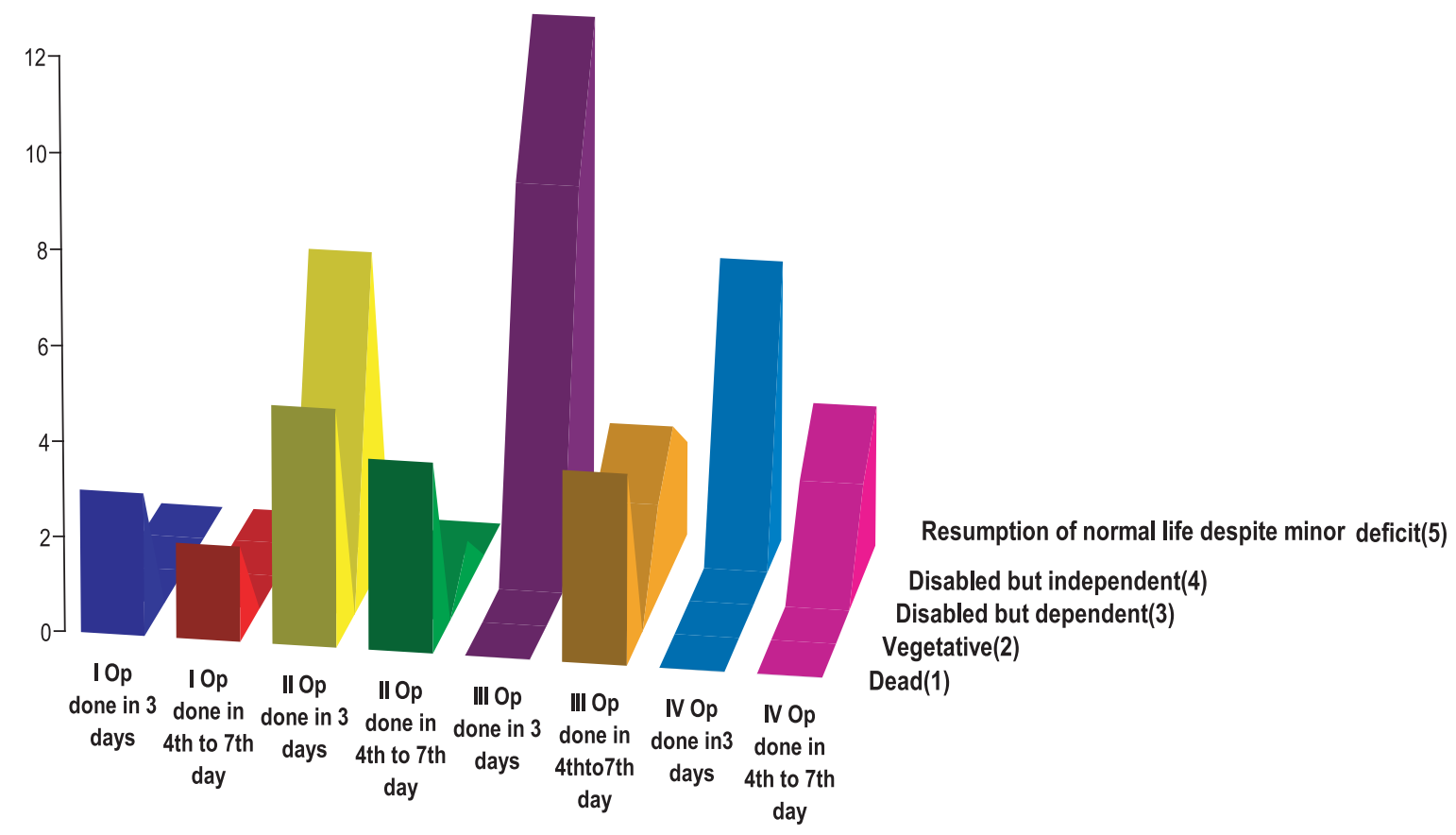

\begin{tabular}{|ll}
\hline I Op done in 3 days & I Op done in 4th to 7th day \\
II Op done in 4th to 7 th day done in 3 days \\
IV Op done in3 days & III Op done in 3 days
\end{tabular}

Table-VII a)

Pre-operative interval and GOS cross tabulation on $8^{\text {th }} P O D$

\begin{tabular}{lccccc}
\hline & & GOS & Total \\
& & 1.00 & 2.00 & 3.00 & \\
\hline Pre-operative interval & Operation done in three days & 8 & 15 & 17 & 40 \\
& Operation done in 4-7 days & 10 & 8 & 5 & 23 \\
\hline Total & 18 & 23 & 22 & 63 \\
\hline For calculation GOS 5 was taken as value 3.00, GOS 4 \& GOS 3 as value 2.00, \\
GOS 1 \&2 as value 1.00.
\end{tabular}

Table-VII b)

Chi-Square Tests

\begin{tabular}{llcc}
\hline & Value & df & Asymp.Sig(2-sided) \\
\hline Pearson Chi-Square & 4.649 & 2 & .098 \\
\hline
\end{tabular}

Pearson Chi-Square was test done. Since ' $p$ ' value $=.098<.1$, at $10 \%$ level of significance.

Significant influence of variation in preoperative interval on variation in outcome on $8^{\text {th }}$ POD. 
Table-VIII a)

GROUP (according to GCS) and GOS Cross tabulation Count on $8^{\text {th }} P O D$

\begin{tabular}{lccccc}
\hline & & GOS & & Total \\
& & 1.00 & 2.00 & 3.00 & \\
\hline GROUP & 1.00 & 14 & 8 & & 22 \\
& 2.00 & 4 & 15 & 22 & 41 \\
\hline Total & & 18 & 23 & 22 & 63 \\
\hline
\end{tabular}

For calculation purpose Group I \& II ( on basis of GCS) was taken as value 1.00, Group III \& IV ( on basis of GCS) as value 2.00 and GOS value as before.

\section{Table-VIII b)}

Chi-Square Tests

\begin{tabular}{cccc}
\hline & Value & df & Asymp. Sig. (2-sided) \\
\hline Pearson Chi-Square & 26.353 & 2 & .000 \\
\hline
\end{tabular}

Since ' $p$ ' value $=0.000$ at any reasonable level of significance.

That is why there is significant influence of variation in GCS level on variation on outcome on $8^{\text {th }}$ POD.

Table-IX a)

Pre-operative interval and GOS Cross tabulation Count after one month.

\begin{tabular}{llcccc}
\hline & & OUT2_2 & Total \\
& & 1.00 & 2.00 & 3.00 & \\
\hline Pre-operative interval & Operation done in three days & 8 & 13 & 19 & 40 \\
& Operation done in 4-7 days & 11 & 7 & 5 & 23 \\
\hline Total & & 19 & 20 & 24 & 63 \\
\hline
\end{tabular}

For calculation GOS 5 was taken as value 3.00, GOS 4 \& GOS 3 as value 2.00, GOS $1 \& 2$ as value 1.00 .

Table-IX b)

Chi-Square Tests

\begin{tabular}{llcc}
\hline & Value & df & Asymp. Sig. (2-sided) \\
\hline Pearson Chi-Square & 6.313 & 2 & .043 \\
\hline
\end{tabular}

Pearson Chi-Square was test done. Since ' $p$ ' value $=.043<.05$, at $5 \%$ level of significance.

There is significant influence of variation in preoperative interval on variation in outcome after one month. 


\section{Table-X}

Number and $\%$ of patients recovers completely (with out minor deficit) where operation was done at different interval. ( Here group I \& II are omitted).

\begin{tabular}{llccc}
\hline Group & Preoperative interval & \multicolumn{3}{c}{ Complete recovery } \\
& & No of patients & Total No & $\%$ \\
\hline III & With in 3 days & 3 & 3 & $4.7 \%$ \\
& With in 5-7 days & & 6 & $9.5 \%$ \\
IV & With in 3 days & 5 & \\
& With in 5-7 days & 1 & \\
G-III & Among 30 pts — complete recovery-3 & & \\
GIV & Among 11 pts—complete recovery-6 & & \\
\hline
\end{tabular}

Table-XI

Number of patients treated in ICU.

\begin{tabular}{lccc}
\hline Group of pt & \multicolumn{3}{c}{ Number of pt actually treated in ICU } \\
& Total no of pt in each group & Total no of patients & $\%$ \\
\hline II & 2 & 7 & $11.1 \%$ \\
III & 4 & & \\
IV & 1 & & \\
\hline
\end{tabular}

Table shows actual number 7 out of 24 patients who need ICU facilities.

Due to very limited number of bed in ICU it was really very difficult to manage all critical cases in ICU.

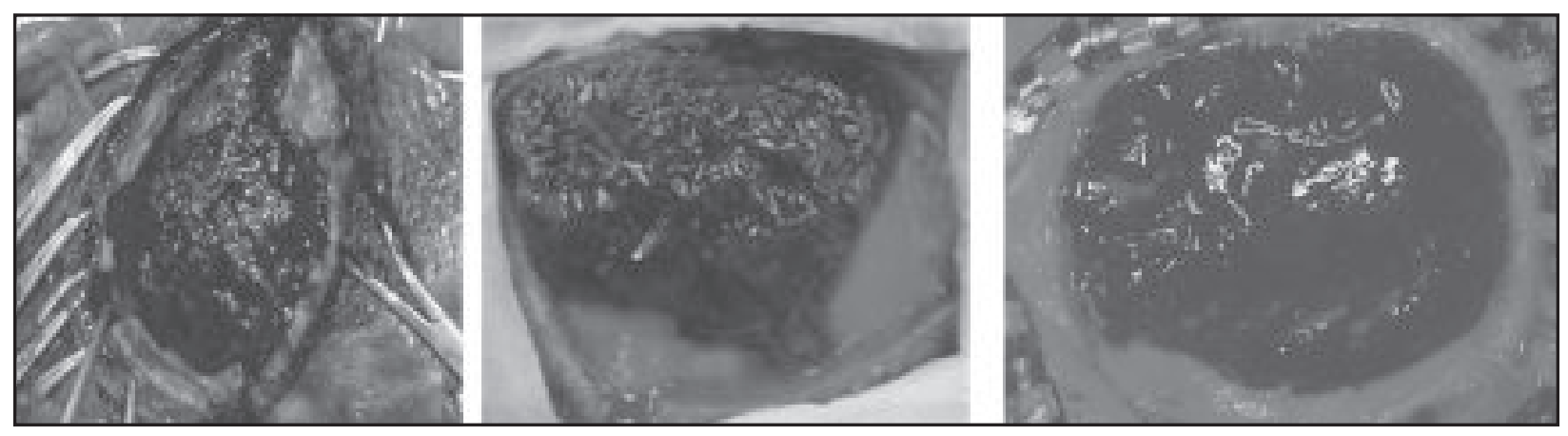

Fig-4: Per operative picture of EDH

\section{Discussion:}

Extra dural haematoma is a unique form of neurotrauma, being potentially lethal yet easily remedied if diagnosed early and treated promptly. For this reason, the outcome of treatment of EDH has remained a yardstick to measure the efficacy of neurotrauma service. ${ }^{7}$ Before introduction of CT, tactics of haematoma treatment was simple: when diagnosed, it was removed as early as possible. ${ }^{8} \mathrm{CT}$
\& MRI allowed to estimate parameters of haematoma, time of its formation, location, type as well as a degree of its impact on the brain. It become possible to exercise dynamic control of evolution of intracranial pathology in general \& haematomas in particular. ${ }^{9} 10$ Majority of the patients belonged to the decades of most active \& productive period of life in our study. Highest percentage of patients 26 cases $(41.3 \%)$ belonged to $3^{\text {rd }}$ decade and 44 cases $(69.8 \%)$ were in 
their most active period of life. We found the age incidence which corresponds to the findings of Servadei $F$, et al who found the peak incidence at 31 yrs in their study..$^{11}$ Males were the major sufferers of the disease, 59 cases (93.6\%) were found in our series where male to female ratio was 14:1. But male to female ratio has been shown $4: 1$ by Greenberg M S 12 \& Ahmad \& Hossain. ${ }^{13}$ Our findings in sex distribution reflects culture of this part of the world where women are less exposed to traffic as they remain mostly confined to household job.We found the cases of EDH were mostly due to RTA (57\%), followed by assault $(26.9 \%)$ and fall from a height $(15.8 \%)$. This data is correlated with the reported series of EDH by Ranga $A$, et al, ${ }^{14}$ but goes in contrary to the study by Grin AA, et al who found it only $18 \% .{ }^{15} \mathrm{Grin} \mathrm{AA}$, loffe Yus, Kry low VV minor traumatic intracranial dural haematoma (up to $50 \mathrm{cc}$ ) of supratantorial location.

This finding indicates urbanization with poor traffic control in this global region, poor design \& maintenance of road, poorly maintained vehicles with no safety facilities, poorly trained drivers \& most importantly public \& children awareness of prevention of accidents play an important role in RTA and head injury including EDH. ${ }^{16}$ In this series 26 cases $(41.2 \%)$ of the EDH were located in the temporal region; followed by frontal region 13 cases $(20.6 \%)$, parietal 11 cases (17.4\%), temporoparietal 10 cases $(15.8 \%)$, and occipital 3 cases (4.76\%). Royal Melbourne Hospital in a series of 200 cases showed $66 \%$ in temporal, $11 \%$ in frontal, $7 \%$ in parietal, $8 \%$ in occipital and $9 \%$ in posterior fossa region. ${ }^{17}$ Murat Hanci, et al. found $39 \%$ of $E D H$ in temporal region, $22 \%$ in frontal region, $18 \%$ in parietal region, $17 \%$ in cerebeller region and $3 \%$ in occipital region. ${ }^{18}$ Both of their finding has got the similarities that they found the temporal EDH in highest percentage of cases , occipital and posterior fossa in lowest percentage. This finding also gives us the impression that adult age group suffered more from temporal or temporoparietal \& frontal EDH. Posterior fossa or occipital location is less common among them.

GCS of the patients were recorded on admission less than 5 in 5 patients(7.9\%), $5-8$ in 15 cases(23.8\%), 9-12 in 29(46\%), $13-15$ in 14 cases(22.2\%). But prior to operation we found $17(26.9 \%)$ patients in GCS 5$8,30(47.6 \%)$ with GCS $9-12$ and $11(17.5 \%)$ with GCS 13-15. This showed that consciousness level was deteriorating in $9.5 \%$ of patients without having decompressive surgery. This finding is consistent with the findings of Borovich, who demonstrated progression of $\mathrm{EDH}$ in $9 \%$ of patients during the first 24 hours. ${ }^{19}$ On the other hand Sullivan TP, et al found $23 \%$ (37 out of 160 patient) of their patients who developed enlargement of EDH within 36 hours.

Nearly similar study was done by Bezirecioglu $\mathrm{H}$, Ersuhin $\mathrm{Y}$ et al \& they found that eighty patients with supratentorial EDH of less than $30 \mathrm{ml}$ volume, while treated conservatively, underwent surgical decompression because of deterioration in the level of consciosness and enlargement of EDH.

One interesting finding was elicited by Jamieson KG \& Yelland JDN, mortality was $29 \%$ in patients undergoing operation within $12 \mathrm{hrs}$ of injury, $4 \%$ in those having surgery between 3 to 4 days after injury and zero mortality in those operated 5 days or more following. This was just reversed the findings of Bricolo AP \& Pasut LM. They found overall mortality $5 \%$ in their study calculated that this low mortality was successfully achieved because $57 \%$ of their patients underwent surgery with in 6 hrs of injury. $60 \%$ was operated with a GCS score between 8 or better. In our series we found overall mortality in 19 cases (30.1\%). All these deaths occur in patients with GCS $<8$ irrespective of time of surgical intervention. But early intervention (mean time interval $24.1 \mathrm{hrs}$ ) gives a significant result. Good recovery (person resume normal life) occurs in 19 cases(30.1\%). Though there was no difference in outcome among the patients in coma and GCS < 8 between the two groups of patients where the mean interval between the injury and operation was significantly different, but we found a significant difference in outcome in patients with GCS 9-12 or GCS 13-15 depending on the time of surgical intervention. This finding correlates to the finding of the Ono J, et al who concluded that in patients with mass lesion, the GCS score was the only significant prognostic factor for the EDH and GCS score could predict outcome in all age groups. Among the patients who were not comatose on admission, a good recovery ( resume normal life) occurs in 24 (38\%) cases in total. Ortler M \& Lang Mayr JJ et al found good recovery in $52 \%$ cases. This discrepancy may be due to delay in our surgical intervention in respect to their patients where interval was only $7 \mathrm{hrs}$. Among 30 patients with GCS 9-12,19 were operated in mean interval of $24.1 \mathrm{hrs}$ and 11 patients operated in interval of 5 days. 13 patients( 20.6\%) out of 19 achieved 
good recovery and 6 cases (9.5\%) achieved moderate disability. On the other hand only two cases $(3.1 \%)$ among those 11 patients with GCS 9-12 who were operated at interval of 5 days achieved good recovery, 3 cases achieved moderate disability, 2 cases with severe disability and 4 were dead .

Patients with GCS score 13-15, when operated earlier (mean interval of $36 \mathrm{hrs}$ ) achieved good recovery in 6 cases ( $9.5 \%$ ) and in 3 cases $(4.7 \%)$ when operated lately. Out come of patients as per GOS ( an international practical scales for evaluation of prognosis of severe head injury) was as follows :

1) Good recovery 24 cases (38\%)

2) Moderate disability 11 cases $(17.4 \%)$

3) Severe disability 9 cases $(14.2 \%)$

4) Dead 19 cases $(30.1 \%)$

Despite a steady decline in mortality to $2.3 \%$ over the past years, we found the overall mortality $30.1 \%$ in this series. While zero percent mortality as proposed by Bricolo and Ammirati (Ammirati M, Tomita T;1985) Ammirati M, Tomita T; Epidural hematomas in infancy and childhood. J Pediatric Neuroscience; 1985; (1; 123-238) is desirable, the difficulties of standardizing emergency services and the frequency of accompanying lesions make this goal difficult to achieve till today in our country.

\section{Conclusion:}

Patients with extradural haematoma may present with only minimal complaints such as headache, nausea \& vomiting. If it is misdiagnosed \& mishandled, it may bring catastrophic events to the patients with respect of mortality and morbidity. In fact these are the patients who "talk \& die" because intracranial haematoma causes secondary deterioration and constitutes over $70 \%$ of death in those patients. Although operative procedure is the main part of treatment, the ultimate outcome of patients depends very much on the progression of the pathophysiological process, its timely modulation and intervention. So early intervention in traumatic EDH cases should not be delayed. It gives not only the better result but also reduces the number of disabled vegetative person and reduces morbidity and above all reduces social burden, hospital staying and cost. I hope this study will open the door for all health personnel specially for young neurosurgeons to think the way out and break through more in this specific field, to reduce the unwanted mortality and morbidity in our country within our limited resources and available facilities.

\section{References:}

1. Eyster E.F, Kelkerd B, PorterR.W. National Center For Health Statistics.Advance Report of Final Mortality Statistics, 1985.WashintonDC US Government Printing Office, 1987.

2. Jamieson KG, Yelland J. D.N: Extradural Haematoma" report of 167 cases. J neurosurg 1968;29,13-23.

3. Kalyanaranaman S, Ramamurthi K, Ramamurthi B: An analysis of two thousand cases of head injury.Neurol (India) 18 (suppl) :3,1970.

4. Ramamurthi B, Tendon PN: Textbook of Neurosurgery, 2nd Ed, Extradural Haematomas, vol-1, B.I.Charchill Livingstone:1996,p297.

5. Jamieson K.G, Yelland J.D.N. : Exradural Haematoma" report of 167 cases. J neurosurg 1968,29;13-23.1968

6. Kalyanaranaman S, Ramamurthi K, Ramamurthi B: An analysis of two thousand cases of head injury. Neurol (India) 18 (suppl):3,1970.

7. Ramamurthy B,Tandon P.N: Extradural Haematomas: Textbook of Neurosurgery : 2nd ed; Churchill Livingstone ;1996 ; vol (1) p 297.

8. Jones NR,Molloy CJ; Kloeden CN: North JB: Simpson DA,.Extradural haematoma: trend in outcome over 35 years, British Journal of Neurosurgery 1993: 7; 465-471.

9. Kotwica Z, Brzezinshi J : Acute subdural haematoma in adults: an analysis of outcome in comatose patients: Acta Neurochir. Wien 1993; vol 121. N3-4: 95-99.

10. Orlin J R, Thuomas K A, Ponten U, et al, MR imaging of experimental subdural bleeding Correlates of brain deformation and tissue water content and changes in the vital physiological parameters,Actra Radiol 1997; vol 38, - N 4. 610620.

11. Orrison W W, Gentry LR, Stimac GK, et al, Blinded comparison of cranial CT \& MRI in closed head injury evaluation. Am. J. Neuroradiol. 1994. - vol 15 N2; 351-356.

12. Servadei F, Vergoni G, Staffa G, Zappi D, Nasi MT, Donati R, Arista A, Extradural haematomas: how many deaths can be avoided? Protocol for early detection of haematoma in minor head injuries : Acta Neurochir (Wien) 1995;133(1-2):50-5 
13. Greenberg M.S.). Handbook of neurosurgery. Epidural haematoma; 4th ed. Greenberg Graphics, 1997, Inc. Vol-II; pp 727-731

14. Ahmed R, Hossain MA: Craniocerebral Trauma; Epidemiology \& Aetiology. Bangladesh Journal of neuroscience, 1989, 5: 66-75.

15. Ranga A, Wani A, Malik AH, Kirmani A, Wani ; Short reports: Acute bilateral extradural haematoma: Neurology india, 2002; 50: 217-218

16. Kumer RM Ch, Shrivastava AKMCh, Singhal U M S, Saraswat B M S*, Mahapatra AKMCh, Compound hed injury in 46 pediatric patients. Indian Journal of Neurotrauma(IJNT) 2009, Vol. 6,No.1,pp. 43-48
17. Kaye, Andrew $\mathrm{H}$ : Essential Neurosurgery, 2nd ed. 1997, pp81-91. Murat H, Mustafa U, Ceng Z $\mathrm{K}$, Aby C Borovich, Braun J, Gilburd JN et all. Delayed onset of extradural hematomas. J Neuro surag;1985; 63;30-34.

18. Sullivan TP, Jarvik JG, Cohen WA; Follow up of conservatively managed epidural haematomas: implications of timing of rapeat CT . Bezircioglu H, Ersahin Y, Demircivi F, Yurf I, Donertask, Tektas S; Non operative treatment of acute extramural haematomas: analysis of 80 cases. J. Trauma 1996, Vol 41, N.4 696-698.

19. Ono J, Yamura A, Kubota M, Okimura Y \& Isobe $\mathrm{K}$ outcome prediction in severe head injury: analysis clinical progressive factors. 